\title{
Immobilization of lactase on modified magnetic chitosan microspheres
}

\author{
Fang Qian ${ }^{1, a}$, Shu-juan Jiang ${ }^{1, b}$, Yang Yang ${ }^{1, c}$, Yanfeng Tuo ${ }^{1, d}$, Guangqing \\ $\mathrm{Mu}^{1,2, \mathrm{e}}$
}

${ }^{1}$ School of Food Engineering, Dalian Polytechnic University, Dalian, 116034, China

${ }^{2}$ Synergetic Innovation Center Of Food Safety and Nutrition, Northeast Agricultural University, Harbin, 150030, China

aqf09@163.com, bjiangsj@dlpu.edu.cn, cyy2007035127@163.com, dtyfjq@aliyun.com, egq6552002@aliyun.com

${ }^{*}$ Corresponding author: Guangqing $\mathrm{Mu}$

\begin{abstract}
Keywords: Immobilization, Lactase, Magnetic fluid, Lactase activity
\end{abstract}
Abstract. The immobilization of lactase is a more attractive approach to overcome the disadvantage of the free lactase. In the presented work magnetic $\mathrm{Fe}_{3} \mathrm{O}_{4}$ fluid was synthesized by chemical coprecipitation and its surface was modified with sodium oleate. Then the liquid paraffin was used as dispersant and glutaraldehyde as cross-linking agent to prepare modified chitosan magnetic microspheres with $\mathrm{Fe}_{3} \mathrm{O}_{4}$ as magnetic core and its outer coated with chitosan through the reversed-phase suspension polymerization method. Finally lactase was immobilized on modified chitosan magnetic microspheres by adsorption and crosslinking with glutaraldehyde. Results indicated the recovery of immobilized lactase was the highest when lactase was immobilized on the modified magnetic chitosan microspheres at $20^{\circ} \mathrm{C}$ for $22 \mathrm{~h}$ and then reacted with $1.0 \mathrm{~mL}$ of $0.4 \%$ glutaraldehyde for crosslinking at $30^{\circ} \mathrm{C}$ for $3 \mathrm{~h}$, and a hydrolysis rate of $38 \%$ was obtained when the immobilized lactase was used to hydrolyze milk at $40^{\circ} \mathrm{C}$ for $3 \mathrm{~h}$.

\section{Introduction}

Galactosidase ( $\beta$-D-galactoside galactohydrolase, EC 3,2,1,23), commercially called lactase, can hydrolyze the $\beta$-D-galactoside linkage to D-glucose and D-galactose, and also catalyze the transgalactosylation of galactooligosaccharides. Lactose that is hydrolyzed in whey and whey permeates are excellent natural sweeteners and can be utilized in frozen desserts, confectionery, bakery, fermented products, and beverages. So lactase is widely applied in food industry to solve the problem of lactose crystallization or shorten the fermentation time of fermented dairy products. In recent years, lactase is used to produce galactose as prebiotic with important physiological function, which have aroused increasing attention[1]. But the application of free lactase has the disadvantage such as poor enzyme stability, easy inactivation and without avaliable reuse, thus greatly increased the cost of production.

Immobilized lactase can overcome the above shortcomings, play a significant role in saving energy resource, reducing costs, protecting the environment, and continuous automation production, 
therefore recently received more attentions. The enzyme immobilization methods were mainly as follows, adsorption, covalent bonding, embedding method and cross-linking method[2]. Lactase immobilized on magnetic chitosan microspheres has been rarely reported in literature.

In the presented work magnetic $\mathrm{Fe}_{3} \mathrm{O}_{4}$ fluid was synthesized by chemical co-precipitation and used to prepare the modified chitosan magnetic microspheres using the reversed-phase suspension polymerization method. Then lactase was immobilized on modified chitosan magnetic microspheres and the optimum conditions for lactase immobilization were investigated.

\section{Materials and Methods}

Materials. Chitosan (degree of deacetylation is 85\%) of food grade was obtained from Dalian Xindie Chitosan Co. Ltd. (Dalian, China), Glutaraldehyde solution in water $(25 \%$, w/w) was purchased from Zhengzhou Third Chemical Reagent Factory (Zhengzhou, China), $O$-Nitrophenyl- $\beta$-D-Galactopyranoside (ONPG), polyethylene glycol (PEG), acetone and liquid paraffin were all purchased from Tianjin Kemiou Chemical Reagent Co. Ltd (Tianjin, China), Sodium oleate was from the Tianjin Fine Chemical Industry Institute (Tianjin, China), Lactase was kindly presented by DSM Relevant Biological Technology Co. Ltd. (Tong xiang, Zhejiang, China), Span-80 was kindly presented by Sinopharm Co. Ltd. (Shanghai, China), and the rest of chemicals used were of analytical grade.

Synthesization of modified magnetic fluid. Magnetic $\mathrm{Fe}_{3} \mathrm{O}_{4}$ fluid was synthesized by chemical coprecipitation[3]. Twenty milliliter of $1 \mathrm{~mol} / \mathrm{L} \mathrm{FeCl}_{2}$ and $\mathrm{FeCl}_{3}$ (v/v, 1:1.5) were mixed under magnetic stirring, then the mixture was heated to $45^{\circ} \mathrm{C}$ and $2 \mathrm{~mol} / \mathrm{L}$ of $\mathrm{NaOH}$ solution was added dropwise to $\mathrm{pH} 9.0$, and the mixture was ripening at $80^{\circ} \mathrm{C}$ for $30 \mathrm{~min}$, and then $30 \mathrm{~mL}$ of $10 \%$ PEG solution was added and cooled with stirring till room temperature Then ten milliliter of anhydrous ethanol was added and kept still for $10 \mathrm{~min}$, the mixture was adjusted to $\mathrm{pH} 6.0$ and reacted with 25 $\mathrm{mL}$ of $0.1 \mathrm{~mol} / \mathrm{L}$ sodium oleate at $80^{\circ} \mathrm{C}$ for $30 \mathrm{~min}$. After reaction the mixture was cooled to room temperature and repeated washing with water and ethanol till the mixture became neutral, and then dried in vacuum. The physical adoption of sodium oleate on $\mathrm{Fe}_{3} \mathrm{O}_{4}$ particles transformed to chemisorption as the reaction temperature increased. The $0.1 \mathrm{~g}$ of modified $\mathrm{Fe}_{3} \mathrm{O}_{4}$ was added to 10 $\mathrm{mL}$ of deionized water, and mixed at $200 \mathrm{w}$ ultrasonic dispersion for $30 \mathrm{~min}$, then the crude extract was separated by the centrifugation at 3,000 rpm for $20 \mathrm{~min}$. The supernatant was measured its absorbance at $600 \mathrm{~nm}$ by spectrophotometer.

Preparation of modified chitosan magnetic microspheres. Modified chitosan magnetic microspheres were prepared with reversed-phase suspension polymerization method[4]. The preparation condition was optimized to obtain an excellent carrier. Ten milliliter chitosan working solution of $0.03 \mathrm{~g} / \mathrm{mL}$ prepared by dissolving the polymers in $1.5 \%(\mathrm{v} / \mathrm{v})$ acetic acid solution was mixed with a certain amount of magnetic fluid containing $0.1 \mathrm{~g}$ modified $\mathrm{Fe}_{3} \mathrm{O}_{4}$ nanoparticles, this solution was subjected to ultrasonic treatment at $200 \mathrm{~W}$ for $30 \mathrm{~min}$, and then was added in dropwise into $16 \mathrm{~mL}$ of liquid paraffin containing $4 \mathrm{~mL}$ of Span-80 (as emulsifier) in a $500 \mathrm{~mL}$ round-bottomed flask by stirring under room temperature. Two milliliter of $10 \%$ (v/v) glutaraldehyde solution was added,to the mixture and stirred at $40^{\circ} \mathrm{C}$ for another $1 \mathrm{~h}$, and then 1 
$\mathrm{mol} / \mathrm{L} \mathrm{NaOH}$ solution was gradually added until the $\mathrm{pH}$ of the mixture reached to be 9.0 10.0, the mixture was reacted at $70^{\circ} \mathrm{C}$ for $2 \mathrm{~h}$. Finally, the products obtained was collected by magnet and washed consecutively with petroleum ether, acetone, distilled water, and then subjected to centrifugal separation and vacuum drying at $60^{\circ} \mathrm{C}$, chitosan magnetic microspheres were obtained for the following research, and its magnetic response was measured[5].

Immobilization of lactase on chitosan magnetic microspheres. The $0.02 \mathrm{~g}$ of modified chitosan magnetic microspheres were pre-equilibrated in phosphate buffer $(0.1 \mathrm{~mol} / \mathrm{L}$ $\mathrm{Na}_{2} \mathrm{HPO}_{4}-\mathrm{NaH}_{2} \mathrm{PO}_{4}$ solution, $\mathrm{pH} 6.86$ ) for $24 \mathrm{~h}$, then $2 \mathrm{~mL}$ of $1 \%$ lactase solution was added in the mixture and immobilized at $20^{\circ} \mathrm{C}$ for $22 \mathrm{~h}$. then were washed with phosphate buffer until no protein in the elution solution was detected. Then $1.5 \mathrm{~mL}$ of $0.4 \%(\mathrm{v} / \mathrm{v})$ glutaraldehyde aqueous solution was added for cross-linking at $30^{\circ} \mathrm{C}$ for $3 \mathrm{~h}$, after reaction the residue glutaraldehyde was removed. The immobilized lactase was then filtered, dried under vacuum and stored at $-4^{\circ} \mathrm{C}$ for further analysis.

Measurement of lactase activity. The activity of free enzyme and immobilized lactase was measured using ONPG method[6].

Condition optimization for lactase immobilization. Lactase activity as a function of glutaraldehyde addition was determined when all the other variables were kept constant in the glutaraldehyde addition range of $0.5 \sim 2.5 \mathrm{~mL}$, Immobilization temperature 4 40, The immobilized time $10 \sim 26 \mathrm{~h}$, crosslinking temperature of $4 \sim 40^{\circ} \mathrm{C}$.

\section{Results and Discussion}

Effect of glutaraldehyde addition. In order to make the excellent reactivity to amino groups possible, the bifunctional cross-linking agent glutaraldehyde was investigated. The effect of different glutaraldehyde addition on lactase immobilization was shown in Fig.1.

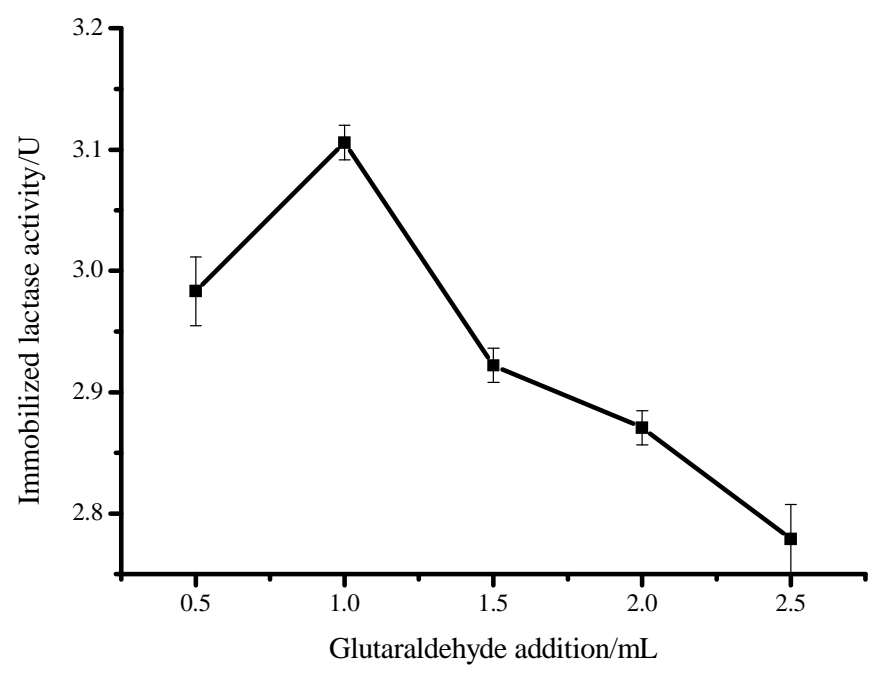

Fig.1 Effect of glutaraldehyde addition on immobilized lactase activity

The Lactase activity as a function of glutaraldehyde was determined when all the other conditions were kept constant in the glutaraldehyde range of $0.5 \sim 2.5 \mathrm{~mL}$. The activity of immobilized lactase 
increased sharply to reach the highest activity of $3.106 \mathrm{U}$ with glutaraldehyde concentration increased, and then decreased when the addition of glutaraldehyde was more than $1.0 \mathrm{~mL}$, which is probably that more glutaraldehyde caused aggregation, precipitation or structural distortion of the enzyme and thus the lactase activity decreased. Therefore, the $1.0 \mathrm{~mL}$ of glutaraldehyde was used for immobilization of lactase in the subsequent experiments.

Effect of immobilization temperature. Figure 2 illustrated the activity of the lactase immobilized at different temperature from 4 to $40^{\circ} \mathrm{C}$. The activity of the immobilized lactase kept increasing with the immobilization temperature increase to $20^{\circ} \mathrm{C}$, which reached a maximum of 3.157 U. Considering that structure conformation plays an important role in the catalytic functions of enzyme, it was probablydue to that immobilization strengthens the lactase molecule's structural rigidity, not only increased stability of the enzyme, but also reduced thermal vibration of the internal group, thus effectively enhance the thermal stability of the enzyme, its activity was also enhanced. However, the limitation of conformational alteration might be responsible for the loss of lactase activity when the lactase was immobilized at higher temperature, the lactase that was immobilized at $40^{\circ} \mathrm{C}$ got the minimum activity of $2.907 \mathrm{U}$. Therefore the suitable temperature for lactase immobilization was $20^{\circ} \mathrm{C}$.

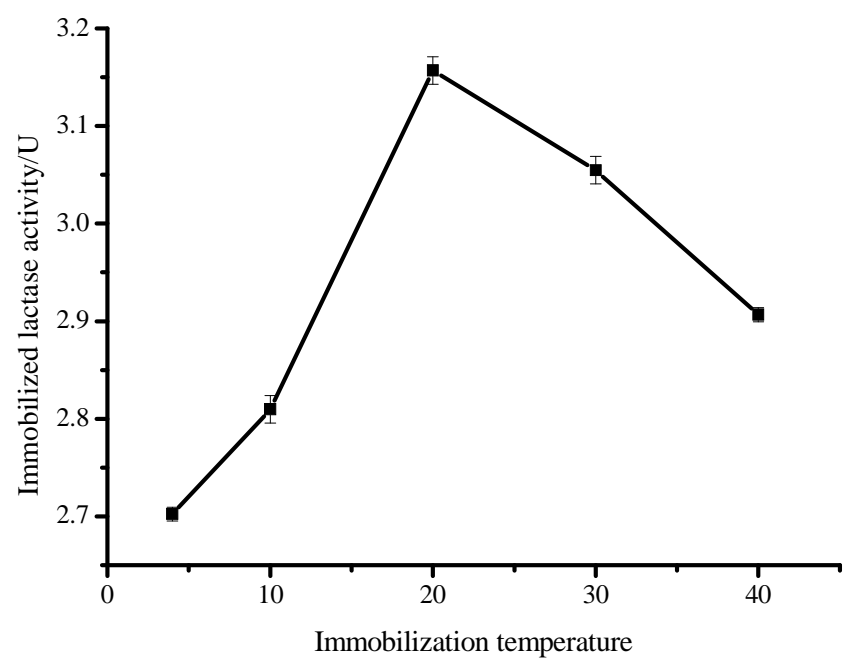

Fig.2 Effect of immobilization temperature on immobilized lactase activity

Effect of immobilization time. Effect of time on lactase immobilization in terms of relative activity was also shown in Fig.3. The activity of the immobilized lactase kept increasing with the prolongation of immobilization time from $2.268 \mathrm{U}$ at $10 \mathrm{~h}$ to $3.315 \mathrm{U}$ at $22 \mathrm{~h}$ when the maximum activity were obtained, So the most suitable immobilization time for lactase was $22 \mathrm{~h}$.

Effect of cross-linking temperature. Temperature is another parameter which strongly affects the activation extent of carrier and the crosslinking of lactase with chitosan magnetic microspheres. To determine the effect of crosslinking temperature, lactase was crosslinked with the carrier under different temperature ranging from 4 to $40^{\circ} \mathrm{C}$. As results shown in Fig.4, the mobilized lactase crosslinked at $4^{\circ} \mathrm{C}$ had the lowest activity of 3.131U, implying that low temperature is not conducive to the cross-linking of lactase with magnetic carrier, then the activity of immobilized 
lactase increased with the cross-linking temperature, when the enzyme activity reached a maximum activity of $3.295 \mathrm{U}$ at $30^{\circ} \mathrm{C}$, thereafter the activity began to decrease with temperature increasing. It could be presumed that suitable temperature leaded to a high amount of protein loading and relative high activity, but some active sites structure of immobilized lactase may be damaged at too high temperature system, namely the denaturation of enzyme. In order to obtain the immobilized lactase with higher activity, $30^{\circ} \mathrm{C}$ was the suitable temperature for the immobilized lactase crosslinking with the chitosan magnetic microspheres.

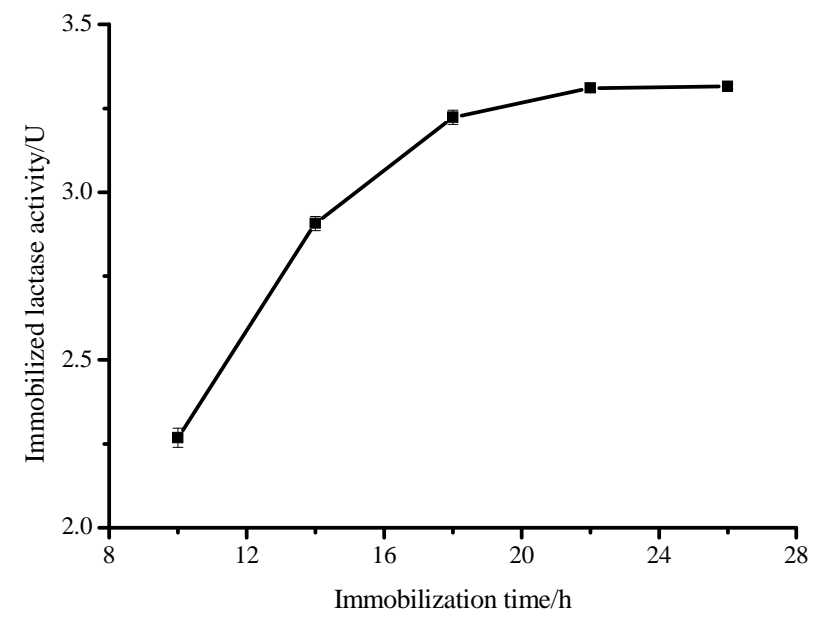

Fig.3 Effect of immobilization time on immobilized lactase activity

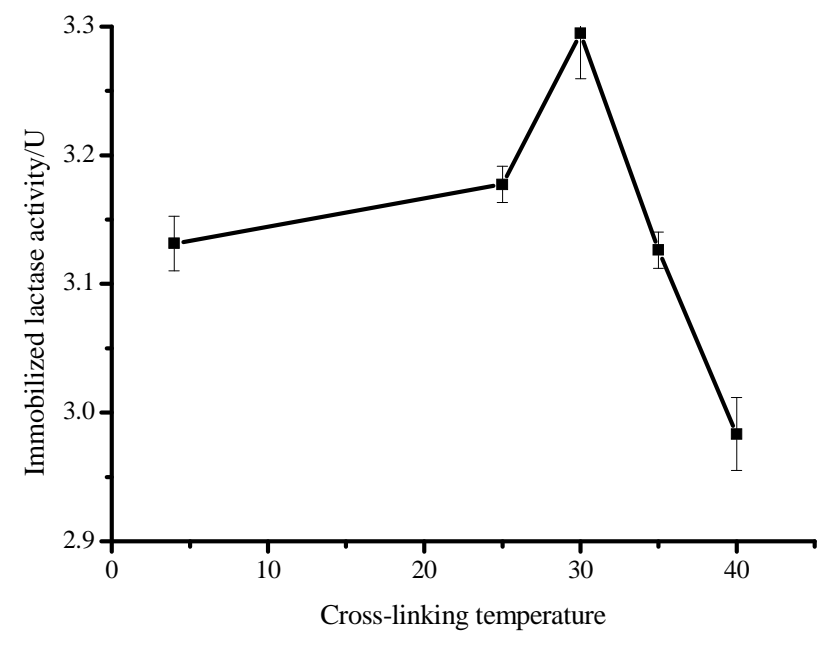

Fig. 4 Effect of crosslinking temperature on immobilized lactase activity

Optimum conditions for lactase immobilization. The optimum conditions for immobilization of lactase on chitosan magnetic microspheres were ascertained: the immobilized lactase had the highest recovery when lactase was immobilized on the swelled chitosan magnetic microspheres at $20^{\circ} \mathrm{C}$ for $22 \mathrm{~h}$, then reacted with $1.0 \mathrm{~mL}$ of $0.4 \%$ glutaraldehyde at $30^{\circ} \mathrm{C}$ for crosslinking $3 \mathrm{~h}$. These results are similar to those of Fang[7] and Qian[8], but lower than that of Fei[4], who linked 1.6 $\mathrm{U} / \mathrm{mg}$ lactase with magnetic chitosan microspheres for $30 \mathrm{~min}$ and then reacted with $0.2 \%(\mathrm{v} / \mathrm{v})$ 
glutaraldehyde at the same temperature for $5 \mathrm{~h}[8]$.

The immobilized lactase prepared in the presented work exhibited good operational and storage stability and a hydrolysis rate of $38 \%$ was obtained when the immobilized enzyme was used to hydrolyze milk at $40^{\circ} \mathrm{C}$ for $3 \mathrm{~h}$, which is lower than that of THP-immobilized $\beta$-galactosidase[9].

\section{Conclusion}

Chitosan magnetic microspheres prepared by reversed-phase suspension method have good paramagnetic characteristics, and its optimum immobilization conditions were immobilization temperature $20^{\circ} \mathrm{C}$, immobilization time $22 \mathrm{~h}, 1.0 \mathrm{~mL}$ of $0.4 \%$ glutaraldehyde addition, crosslinking temperature $30^{\circ} \mathrm{C}$.

\section{Acknowledgements}

This study was funded by National Science and Technology Pillar Program during the Twelfth Five-year Plan Period (2013BAD18B04), Liaoning Province Natural Science Foundation Projects (201602053), National Natural Science Foundation Projects (31501513), National Engineering Research Center of Seafood (2012FU125X03), Key University Science and Technology Platform of Liaoning Province (No. 2011-191), and Liaoning Province Natural Science Foundation Projects (2014026018).

\section{References}

[1] H. Wu, S.H. Yang, High performance thin layer chromatography analysis of galacto-oligosaccharide and other sugars in the syrup, Chinese Dairy Industry, Vol. 29(2) (2001), p.25-28 (in Chinese).

[2] Z.H. Sun, Biocatalysis Technology, Chemistry Industry Publisher, Beijing, 2005, p.22-23 (in Chinese).

[3] L. Wang, Z. Liu, L. Wang, Preparation and characterization of modified magnetic chitosan microspheres and its characteristics, Applied Chemical Industry, Vol. 36(2) (2007), p.105-108 (in Chinese).

[4] Y. Fei, Lactase immobilized on the magnetic chitosan microspheres and its application in lactulose production. M. Sc. Thesis. Jiangnan University, Wuxi, China, 2008 (in Chinese).

[5] X. Bian, Y. Zhao, Y. Meng, Z. Cai, Influence of surfactants on the stability and coated structures of magnetic fluids, Materials Review B, Vol. 26 (2012), p. 92-96 (in Chinese).

[6] H. Li, T. Cheng, Biological activities of glycomacropeptide in milk, Chinese Dairy Industry, Vol. 30(5) (2002), p.74-77 (in Chinese).

[7] H. Fang, Preparation of magnetic chitosan nanoparticles and immobilization of lactase. J. Wuhan University of Science and Technology, Vol. 24 (2007), p.42-45 (in Chinese).

[8] T. Qian, Immobilization of lactase on modified chitosan magnetic microspheres. M. Sc. Thesis. Jiangnan University, Wuxi, China, 2010 (in Chinese).

[9] W. Chen, H. Chen, Y. Xia, J. Yang, J. Zhao, F. Tian, H. Zhang, Immobilization of recombinant thermostable $\beta$-galactosidase from Bacillus stearothermophilus for lactose hydrolysis in 
milk. Journal of Dairy Science, Vol. 92(2) (2009), p.491-498. 